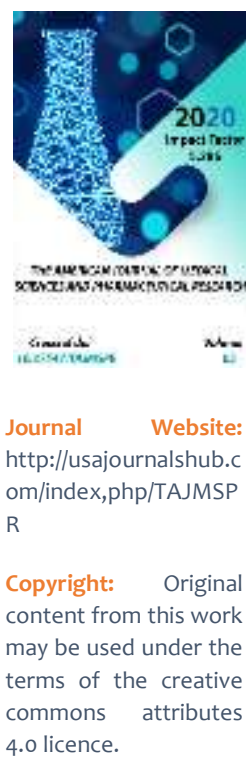

\title{
Problems Associated With Dental And Dental Diseases
}

\author{
Oblokulov Axmad Tilavkulovich \\ Samarkand State Medical Institute Assistant At The Department Of Pediatric Dentistry, \\ Uzbekistan
}

Saidmurodova Jamila Botirovna

Samarkand State Medical Institute Assistant At The Department Of Pediatric Dentistry, Uzbekistan

Bayzakova Sitora Mavlanovna

Samarkand State Medical Institute Assistant At The Department Of Pediatric Dentistry, Uzbekistan

\section{ABSTRACT}

This article is mainly about dental thieves and the full information about the diseases that arise from them. The article describes various treatments and recommendations for dental diseases.

\section{KEYWORDS}

Tooth, dental diseases and its prevention, pain in the tooth, consumption of products

\section{INTRODUCTION}

Causes of toothache:

In the early stages of tooth decay, the pain in the tooth will be imperceptible or not at all, pain occurs during the consumption of sweet and sour products, as a result of hot and cold effects. When caries deepens, toothache appears during eating and during tooth washing.
The thinning of the tooth enamel or the presence of cracks in it increases the sensitivity of the teeth.

In inflammation of the pulp Pulp (soft tissue inside the tooth), pain occurs unexpectedly (usually at night) and can pass to the jaw or ear. The pulp is called more "dental nerve" among 
the people, but this is an erroneous opinion, since in addition to the nerve in the pulp there is also more vascular, lymph, connective tissue.

Periodontitis - inflammation of the tissues around the tip of the tooth-parading. Pain often has a caressing nature, pain when touching a tooth, gums. Inflammation of the gums can be observed along with a sharpening of the tooth.

Periodontitis-inflammation of the bone tissue around the tooth, most often occurs as a result of the fall of the infection, a tooth cyst may form.

A variety of drugs against toothache the most effective NYQV-ketoprofen ("Keaton"," Ketorolac"," ketorolac", etc.) or dexketoprofen ("Dealing") are preservatives for pain relief. These drugs can relieve toothache for 5-6 hours and have an antiinflammatory effect at the same time. It is also worth noting that Ibuprofen (Noreen, MIG, Aspic, etc.), Naproxen (Sanaprox, Naris) and Flurbiprofen (Flailing) in this group of propionic acid flour are also acceptable.

Very strong analgesic and anti-inflammatory drugs remain diclofenac and acyclofenac, they belong to the group of phenylcyric acid derivatives, but in dentistry these drugs are not widely used.

Among the widely used and effective toothache-relieving drugs, there is also nimesulide (Nays), it is included in the group of sulfonamides, more precisely, in the number of acid-free Unum. One of the leaders in antitooth pain drugs remains indicating, which has an anti-inflammatory and very high painrelieving effect.

The most optimal drugs for relieving toothache are anlagen and paracetamol, but they are able to help only in cases of mild pain.
These drugs are not recommended to be used in early childhood, during pregnancy (except for paracetamol, it can be used starting with the second trimester) and in old age. Since most of these drugs are acidic NYQV, they affect the gastrointestinal tract, so it's good that they are taken in moderation, if there are ulcers and erosions, acute diseases of the liver and kidneys, bronchial asthma, it is recommended not to use them at all. You may need pain medications or antibiotics after dental implant surgery. If swelling, discomfort or any other problem gets worse in the days after surgery, contact your oral surgeon.

After each stage of surgery, you may need to eat soft foods while the surgical site heals. Typically, your surgeon will use stitches that dissolve on their own. If your stitches aren't self-dissolving, your doctor removes them.

\section{RESULTS}

Most dental implants are successful. Sometimes, however, the bone fails to fuse sufficiently to the metal implant. Smoking, for example, may contribute to implant failure and complications. If the bone fails to fuse sufficiently, the implant is removed, the bone is cleaned up, and you can try the procedure again in about three months.

You can help your dental work - and remaining natural teeth - last longer if you:

\section{CONCLUSION}

Practice excellent oral hygiene. Just as with your natural teeth, keep implants, artificial teeth and gum tissue clean. Specially designed brushes, such as an interdental brush that slides between teeth, can help clean the nooks and crannies around teeth, gums and metal posts. 
See your dentist regularly. Schedule dental checkups to ensure the health and proper functioning of your implants and follow the advice for professional cleanings.

Avoid damaging habits. Don't chew hard items, such as ice and hard candy, which can break your crowns - or your natural teeth. Avoid tooth-staining tobacco and caffeine products. Get treatment if you grind your teeth.

\section{REFERENCES}

1. Elizarova V. M., Drobotoko L. N., Strakhova S. Yu. / / Lech. doctor. - 2000. - no. 8. - P. 2729.

2. Isakov V. A., Rybalkin S. B., Romantsov M. $G$. herpesvirus infection: a manual for doctors. - SPb., 2006. - 95 p.

3. Levonchuk E. A. herpetic infection of a polostyrta // Tell lies. dentistry. - 2005. №1. - C.19-23

4. Looker, KJ; Garnett, GP; Schmid, GP (October 2008). "An estimate of the global prevalence and incidence of herpes simplex virus type 2 infection". Bulletin of the World Health Organization. 86 (10): 805-12, A.

5. Dickerson FB, Boronow JJ, Stallings C, et al. (March 2004). "Infection with herpes simplex virus type 1 is associated with cognitive deficits in bipolar disorder". Biol. Psychiatry. 55 (6): 588-93.

6. Rapini, Ronald P.; Bolognia, Jean L.; Jorizzo, Joseph L. (2007). Dermatology: 2Volume Set. St. Louis: Mosby. ISBN 978-14160-2999

7. Baratova sh. N., Rakhimberdiev R. A., Shamsiev R. A. "Features of the course and diagnosis of dental caries in children of primary school age". Achievements of science and education-scientific and methodological journal, 2020, no. 1 (55), pp. $83-88$
8. Ubaidullaeva M. A., R. A. Rahimberdiev, Shamsiev.And . "Hygienic care of the oral cavity in children of early age". Achievements of science and educationscientific and methodological journal, 2020, no. 1 (55), pp. 88-94

9. Baratova sh. N., Rakhimberdiev R. A., Shamsiev R. A. "Prevention of permanent dental caries in children of primary school age". Achievements of science and education-scientific and methodological journal, 2020, no. 4 (58), pp. 67-75

10. Zubaydullayeva M. A., Rakhimberdiev R. A. "dental Caries in young children: epidemiology, etiology, prevention, treatment". Achievements of science and education-scientific and methodological journal, 2020, no. 4 (58), pp. 79-88

11. Indiaminova G.N., Zoirov T.E. "Optimization of the provision of dental care for mentally retarded children in special support schools" Journal of Natural Remedies, JNR Online Journal ISSN: 23203358 (e) ISSN: 0972-5547(p), Vol. 21, No. 6, (2020), 84-86 pages

12. Shukurov Sh. Sh., Arzykulova M. Sh., Axrorova M. Sh. "Transitional features of acute herpetic stomatitis in children and modern approaches to treatment" The American journal of medical sciences and pharmaceutical research. The USA Journals, USA ISSN 2689-1026, Volume 2 Issue 9, 2020, 15-18pages

13. Oblokulov A. T., Rakhimberdiev R. A. "Optimization of treatment of acute herpetic stomatitis in school-age children". Journal of Biomedicine and practice, 2020, special issue-2, pp. 799-802

14. Indiaminova G. N. "Terms of orthodontic treatment in patients with dentoalveolar anomalies with and without removal of separate teeth". Journal of Biomedicine 
and practice, 2020, special issue-2, pp. 803-

806

15. Oblakulov A. T., Saidmurodov J. B. "Herbal medicine in the treatment of acute herpetic stomatitis in children". Re-health electronic scientific and practical journal, 2020, no. 2.2 (6), pp. 130-133

16. Oblokulov A. T., Saidmurodova Zh. b. "Evaluation of the effectiveness of therapeutic pads based on calcium hydroxide in the treatment of deep caries in children" Re-health electronic scientific and practical journal, 2020, no. 2.3, pp. 115118 